\title{
Sub-registro de nascimentos vivos hospitalares em área urbana da região sul do Brasil, em 1989*
}

\section{Under registration of hospital live births in an urban area of Southern Brazil, 1989}

\author{
Regina K. Tanno de Souza**, Sabina L.D. Gotlieb"** \\ SOUZA, R.K.T. de \& GOTLIEB, S.L.D. Sub-registro de nascimentos vivos hospitalares em área \\ urbana da região sul do Brasil, em 1989. Rev. Saúde Pública, 27: 177-84, 1993. Com o objetivo \\ de avaliar a real situação do Registro Civil, no Município de Maringá, PR, Brasil, foram estudados \\ 4.876 nascimentos vivos ocorridos nos seus hospitais, em 1989, filhos de mulheres nele residentes. \\ São apresentadas as etapas que permitiram identificar, dentre a populaçāo de estudo, os \\ nascimentos registrados (mesclagem de dois arquivos). A estimativa máxima da taxa de \\ sub-registro, no primeiro ano de vida, foi igual a $9,1 \%$, variando segundo idade da mãe (quanto \\ mais jovem, maior a taxa), situação previdenciária (indigentes com a maior estimativa) e paridade \\ (primíparas, menor valor), permitindo aventar a hipótese de associação entre sub-registro e piores \\ níveis socioeconômicos.
}

Descritores: Sub-registro. Certidão de nascimento. Estatísticas de natalidade.

\section{1 - Introduçăo}

O diagnóstico do nível de saúde de uma comunidade é tarefa imprescindivel para que açōes de saúde pública sejam planejadas e avaliadas. São, então, utilizados indicadores de saúde, de qualidade de vida e aqueles que medem a oferta e qualidade de serviços de saúde existentes na área em estudo.

Alguns indicadores utilizam na sua construção dados de eventos vitais como nascimentos vivos, óbitos, entre outros. Um dos indicadores tradicionalmente usado é o coeficiente de mortalidade infantil (CMI), calculado a partir dos dados do Registro Civil, relacionando os totais de óbitos menores de um ano e de nascidos vivos, ambos registrados e ocorridos em determinada área e período.

\footnotetext{
* Parte de Dissertaçâo apresentada ao Departamento de Epidemiologia da Faculdado de Saúde Pública da Universidade de São Paulo, para a obtenção do título de Mestre em Saúde Pública. Projeto financiado pela FAPESP, processo 91/3069-0

** Departamento de Enfermagem da Fundação Estadual de Maringá - Maringá, PR - Brasil

*** Departamento de Epidemiologia da Faculdade de Saúde Pública da Universidade de São Paulo - São Paulo, SP . Brasil
}

Separatas/Reprints: R.K.T. de Souza - Av. Colombo, 3690 87020 - 900 - Maringá, PR - Brasil

Edição subvencionada pela FAPESP. Processo Medicina 93/ 0208-5.
Esses dados, entretanto, podem apresentar falhas, principalmente em locais menos desenvolvidos. Tal integridade questionável, do ponto de vista qualitativo e/ou quantitativo, recomenda cuidados na leitura dos dados oficiais, pois, dependendo da magnitude desses erros, podem ter profundas implicaçס̃es nas estimativas do CMI e sua possível análise.

Laurenti e col. ${ }^{3}$, reconhecendo a importância desse indicador e as possibilidades de distorções em seu cálculo, têm apontado os principais erros, destacando-se, entre outros, o sub-registro de nascimentos e o sub-registro de óbitos de menores de um ano.

Entre as razões para o não-registro, destacamse a de ordem financeira, a negligência e a falta de conhecimento de sua importância ${ }^{3}$. Tais situações tornam o sub-registro (omissão do registro legal) problema concreto e a sua mensuração é questão a ser considerada quando são utilizadas as estatisticas vitais.

Vários trabalhos, desde a década de 40 , têm mostrado altas taxas de sub-registro de nascimento, em diversas áreas do país, e apresentam amplitude variando de $8 \%$ a $68,4 \%$ (Tabela 1 ). As referências bibliográficas citadas no presente artigo destacam esses aspectos.

O sub-registro de óbitos de menores de um ano pode ocorrer em duas situações: existência de cemitérios clandestinos ou erro na definição de um concepto que nasce com vida e vai a óbito logo após o nascimento, sendo classificado pelo médico como nascido morto. A primeira situação dificil- 
Tabela 1. Estimativas da taxa de sub-registro de nascidos vivos, em algumas áreas do Brasil, 1945/1989.

\begin{tabular}{|c|c|c|c|c|}
\hline Autor & Ano & Metodologia & Area & Taxa de sub-registro \\
\hline Saade, M. J. ${ }^{7}$ & $1945 / 6$ & $\begin{array}{l}\text { Comparação com } \\
\text { outras fontes }\end{array}$ & Vitória, ES & $38,0 \%$ \\
\hline Scorzelli8 & 1945 & $\begin{array}{l}\text { Comparação com } \\
\text { outras fontes }\end{array}$ & $\begin{array}{l}\text { Manaus, AM } \\
\text { Belém, PA } \\
\text { Recife, PE }\end{array}$ & $\begin{array}{l}60,0 \% \\
40,0 \% \\
50,0 \%\end{array}$ \\
\hline Laurenti ${ }^{3}$ & 1965 & $\begin{array}{l}\text { Pesquisa domici- } \\
\text { liária (amostra) }\end{array}$ & $\begin{array}{l}\text { Distrito de } \\
\text { São Paulo }\end{array}$ & $\begin{array}{l}4,5 \% \text { (até } 15 \mathrm{~d} \text { ) } \\
3,2 \% \text { (até } 45 \mathrm{~d} \text { ) }\end{array}$ \\
\hline Suarez, L. ${ }^{12}$ & 1968 & $\begin{array}{l}\text { Comparação com } \\
\text { serviço de verifi- } \\
\text { caçąo de óbitos }\end{array}$ & $\begin{array}{l}\text { Distrito de } \\
\text { Săo Paulo }\end{array}$ & $17,9 \%$ \\
\hline $\begin{array}{l}\text { Investigação inter- } \\
\text { americana de mortalidade } \\
\text { na infância } 4\end{array}$ & $1968 / 70$ & $\begin{array}{l}\text { Pesquisa domici- } \\
\text { liária (amostra) }\end{array}$ & $\begin{array}{l}\text { Distrito de } \\
\text { Sáo Paulo }\end{array}$ & $\begin{array}{c}5,5 \% \text { (até } 15 \text { d) } \\
3,7 \% \text { (até } 60 \text { d) } \\
4,6 \% \text { (hosp.) } \\
14,3 \% \text { (dom.) } \\
9,5 \% \text { (óbito de } 1 \text { ano) }\end{array}$ \\
\hline Monteiro, A. 5 & 1972 & $\begin{array}{l}\text { Pesquisa domici- } \\
\text { liária (amostra) }\end{array}$ & Araraquara, SP & $8,5 \%$ \\
\hline Trabalho de campo 13 & 1972 & $\begin{array}{l}\text { Pesquisa domici- } \\
\text { liária (amostra) }\end{array}$ & $\begin{array}{l}\text { Presidente } \\
\text { Venceslau, SP }\end{array}$ & $10,0 \%$ \\
\hline Fundação IBGE10 & 1972 & $\begin{array}{l}\text { Pesquisa domici- } \\
\text { liária (amostra) }\end{array}$ & Brasil & $\begin{array}{l}27,3 \% \text { (urbano) } \\
54,4 \% \text { (rural) }\end{array}$ \\
\hline $\begin{array}{l}\text { Secretaria de Saúde do } \\
\text { Estado }\end{array}$ & 1974 & $\begin{array}{l}\text { Pesquisa domici- } \\
\text { liária (amostra) }\end{array}$ & $\begin{array}{l}\text { Rio Grande do } \\
\text { Sul }\end{array}$ & $\begin{array}{l}34,6 \% \text { (geral) } \\
28,8 \% \text { (urbano) } \\
40,4 \% \text { (rural) }\end{array}$ \\
\hline Almeida, M.M.G.1 & 1977 & $\begin{array}{l}\text { Pesquisa domici- } \\
\text { liária (amostra) }\end{array}$ & Salvador, BA & $32,0 \%$ \\
\hline Barros, F. ${ }^{2}$ & 1982 & $\begin{array}{l}\text { Comparação com } \\
\text { registros }\end{array}$ & Pelotas, RS & $8,0 \%$ \\
\hline Portela, M.H. ${ }^{6}$ & 1985 & $\begin{array}{l}\text { Comparação com } \\
\text { dados da F. SESP }\end{array}$ & Piripiri, PI & $68,4 \%$ (F. SESP) \\
\hline
\end{tabular}

mente poderia estar interferindo nas estatísticas vitais de Maringá, $P R$, visto que sepultamentos nos cemitérios locais ocorrem somente mediante a apresentação da certidão de óbito, isto é, quando a morte for oficialmente registrada. A segurida, referente ao erro na definição, é um problema a ser considerado. No entanto, a mensuração da magnitude deste problema não é objeto do presente estudo. Porém, relativamente ao sub-registro de nascimento, há interesse em conhecer se, em Maringá, também ele existe e, em caso afirmativo, estimá-lo para que seja possivel analisar os dados que servem de subsídio ao planejamento e avaliação das ações de saúde pública, sob uma perspectiva crítica.

O presente trabalho tem por objetivo estimar a taxa de sub-registro de nascimentos vivos hospitalares, filhos de mulheres residentes em Maringá, PR, em 1989, segundo sexo, idade, paridade e si- tuação previdenciária da mãe e tipo de parto, e analisar os registros oficiais segundo declarante e tempo entre o nascimento e seu registro civil.

\section{2 - Materlal e Método}

\section{1 - Populaçāo de Estudo e Fonte de Dados}

A população de estudo foi constituída por 4.876 nascimentos vivos, cujos partos se realizaram nos hospitais do Município de Maringá, PR, entre 1 de janeiro e 31 de dezembro de 1989, filhos de mulheres residentes no citado Município.

Em relação aos nascimentos hospitalares, foram consultados prioritariamente os livros de registro existentes em seis hospitais (um hospital não faz anotação em livro); em seguida, o livro da materni- 
dade e o prontuário médico, seqüencialmente, para complementar as informaçoes.

Relativamente aos registros de nascimento, foram consultados os livros de registros dos quatro cartórios do Registro Civil do Município.

\section{2 - Procedimentos}

O levantamento dos dados foi realizado em duas planilhas (uma para cada fonte) e os dados, já no ato, eram codificados, conforme padronização prévia.

Nos hospitais, para cada caso, foram coletados: nome, idade e vínculo previdenciário da mãe, tipo de parto, ordem de nascimento, sexo e data de nascimento da criança. Cuidado especial foi tomado quanto ao nome da mãe, por se tratar de informação de importância capital na identificação da criança. Note-se que o preenchimento do livro é manual, possibilitando inúmeras distorçð̃es em sua grafia, associada à pouca importância dada, em nível hospitalar, à transcrição graficamente correta. Embora muitos nomes conservem sua possibilidade de identificação, são freqüentes as omissões de letras ou partes de nomes ou sobrenomes.

Foram excluídos da coleta os nascimentos que continham a observação "nascido morto", "feto morto" ou "natimorto" e os que fizessem menção à residência em outro município. Desta última questão, um problema que surge é o do fornecimento de diferentes endereços à medida que a parturiente oriunda de outro município refere, $n^{2}$ internação, endereço em Maringá; quando indagada, na maternidade, relata o município real de sua procedência, ou vice-versa (endereço real na internação e o de referência na maternidade). Como nos hospitais não existem restriçð̄es às parturientes que as conduzam a adulterar o endereço, qualquer referência a outras localidades, nas fontes consultadas, foi considerada suficiente para excluir o caso.

Desta forma, dos hospitais foram levantados 4.978 nascidos vivos, sendo ainda uma população provisória.

Paralelamente à coleta nos hospitais, realizouse a dos cartórios. Desta fonte foram de interesse os seguintes dados: datas de nascimento e do registro, o declarante, local em que ocorreu o parto, nome e idade da mãe, sexo e o nome da criança, como uma informação adicional. Foram excluídas todas as crianças cuja residência materna era fora de Maringá e o ano de nascimento diferente de 1989. O levantamento estendeu-se até os registros efetuados em 31 de dezembro de 1990, assegurando, desta forma, que todas as crianças do estudo que tivessem o registro de nascimento até completar um ano de idade fossem consideradas registradas. Totalizaram nos cartórios, 4.849 registros civis de nascidos vivos.
Apesar do estudo delimitar somente os nascidos vivos hospitalares, participaram desta "fase" todos os registros referentes a filhos de mulheres residentes, inclusive partos domiciliares e nascimentos em hospitais de outros municípios, tendo em vista as possibilidades de distorções decorrentes das determinaçôes legais quanto ao local de registro.

Todos os dados coletados nos hospitais e cartórios foram, respectivamente, armazenados em dois arquivos e, posteriormente, comparados com a finalidade de localizar as crianças registradas entre as nascidas vivas nos hospitais.

O reconhecimento de uma criança constante no primeiro arquivo (hospital) e no segundo (cartório) foi feito pela data de nascimento (dia/mês/ano) e nome completo da mãe.

De acordo com o programa de computação desenvolvido, o emparelhamento pretendido foi possivel somente naqueles casos em que o nome da mãe e a data de nascimento eram perfeitamente coincidentes (caracter por caracter). A Figura esquematiza o emparelhamento viabilizado, com destaque na faixa referente ao registro efetuado.

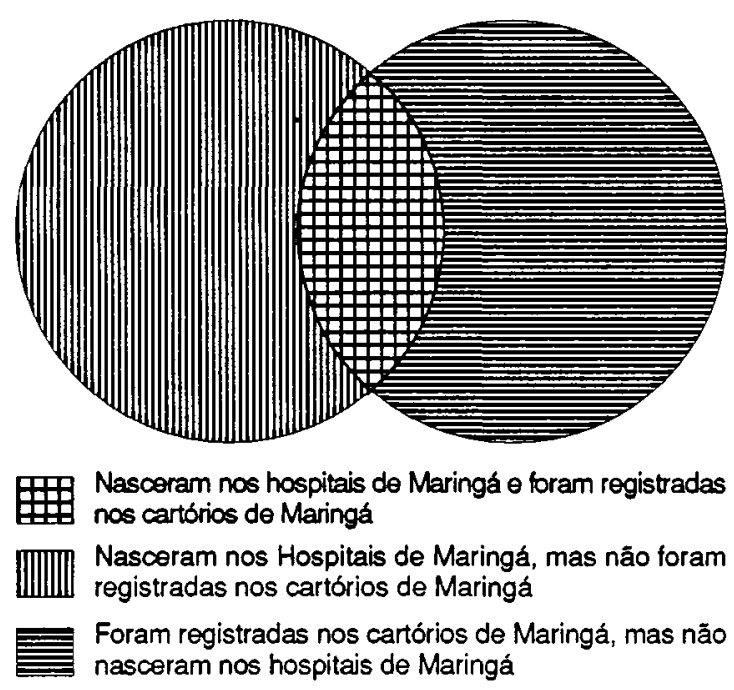

Figura. Representação esquemática do emparelhamento hospital e cartório.

Em uma primeira tentativa, somente $44 \%$ dos casos hospitalares foram localizados entre os registrados. Este resultado e o conhecimento prévio da pouca valorização do nome da mãe apontaram a necessidade da comparação, caso a caso, dos dados que eram comuns aos arquivos (data e local de nascimento, nome e idade da mãe e sexo da criança), sendo que critérios de decisão, quanto à fonte mais adequada, foram então definidos: 
1. Nome da mäe: con'stante do cartório, tendo em vista as implicaçőes legais decorrentes de filiaçōes erroneamente declaradas.

2. Idade da mäe: aquela apresentada no hospital, por interessar a idade por ocasião do parto.

3. Data de nascimento: informação do hospital, pois dificilmente apresenta distorção, tendo em vista a sistemática de anotação no livro do berçário. Já no cartório, como não há exigência de um documento comprobatório do nascimento, é muito fácil adulterar esta (ou qualquer outra) informação, principalmente se se considerar que, ao registro tardio, vincula-se uma multa.

4. Sexo: de acordo com o registro civil; em casos de dúvidas, recorreu-se ao nome dado à criança.

5. Local de nascimento: o constante no hospital.

6. Residência em Maringá: constante do hospital e cartório; a menção de endereço fora do $\mathrm{Mu}$ nicípio, em qualquer uma das fontes, foi considerada suficiente para excluir o caso, pois o fato de residir em outros municípios não constitui impedimento seja à internação hospitalar ou ao registro que, conforme determinaçőes legais, deve ser efetuado no local de ocorrência. É provável que residentes em outros municípios forneçam no hospital ou no cartório, endereço de referência em Maringá.

Norteados por esses critérios, partiu-se para a correção e tentativas de emparelhamento, realizadas em várias etapas. Esgotadas todas as possibilidades de correção, estimou-se a taxa de sub-registro.

A mensuração da taxa de sub-registro de nascimentos hospitalares foi feita através do conhecimento do número de nascidos vivos hospitalares, sem registro civil, relacionados ao total de nascidos vivos em hospital.

O periodo estabelecido para que ocorresse o registro foi de um ano, portanto, a estimativa da taxa de sub-registro representa a percentagem de crianças nascidas vivas em hospitais de Maringá, filhos de mulheres aí residentes e que não foram registradas no primeiro ano de vida.

A taxa de sub-registro refere-se a essa população; no entanto, pelo fato de os partos hospitalares representarem quase a totalidade dos nascimentos do Município, é bastante provável que os dados reflitam a realidade maringaense.

\section{3 - Análise Estatística}

Para verificar a associação entre a taxa de subregistro de nascimentos e as variáveis de estudo foi utilizada a distribuição Qui-quadrado. O nível de significância foi fixado em $5 \%$. Destaca-se que 0 intervalo de tempo entre o nascimento e o registro foi dicotomisado em prazo legal (até 15 dias para o pai ou até 60 dias quando o declarante é a mãe ou outra pessoa, conforme lei $n^{2} 6015$ de 31/ $12 / 1973)^{3}$ e fora do prazo legal.

\section{3 - Resultados e Discussáo}

O presente estudo permitiu estimar, para 1989. uma taxa de sub-registro de nascimento de $9,1 \%$, referente ao total de partos hospitalares de mulheres residentes em Maringá, seguidos até que o nascido vivo completasse o primeiro ano de vida. Esta taxa foi obtida após várias tentativas de localização dessas crianças nascidas em hospitais, entre as registradas.

Dos 4.978 nascidos vivos (prováveis residentes segundo o hospital), 107 foram excluídas pois não correspondiam à população selecionada para o estudo, sendo que destas, 102 crianças não foram incluídas por terem mães residentes fora do Município. Esclarece-se que apesar das anotaçðes hospitalares referirem residência em Maringá, por ocasião do registro oficial 98 forneceram o endereço de outras localidades (remota a possibilidade de ter havido mudança de endereço no intervalo de tempo entre o nascimento e o registro civil, tratando-se, em sua maioria, de registros efetuados dentro do prazo legal) e 4 que foram a obito no periodo intra-hospitalar, constando na declaração de óbito, residência fora de Maringá. Das restantes exclusões (5), quatro referem-se a perdas fetais que haviam sido incluídas no estudo por não estar explícita a condição do nascimento (se vivo ou morto) no hospital, mas foram registradas como natimortos, com causas básicas (feto macerado, anóxia intraútero) e peso ao nascer -560 gramas- que confirmam, em certa medida, o registro efetuado; e um foi retirado por se tratar de parto domiciliar e a criança havia sido encaminhada ao hospital, logo após o nascimento.

Foram acrescentadas ao estudo mais cinco crianças que haviam sido excluídas por ocasião da coleta no hospital. Tais inclusōes foram baseadas nas declaraçōes de óbito e livro de registro civil. Segundo anotaçōes hospitalares, 3 casos continham a observação "natimortos", mas foram registrados como nascidos vivos que faleceram nas primeiras horas de vida; outras duas crianças eram filhas de mulheres não residentes, mas, a Declaração de Óbito (D.O.) fazia referência a endereço em Maringá.

Em resumo, a população estudada foi constituída de 4.876 nascidos vivos, provenientes de partos em hospitais do Município, filhos de mulheres residentes, no ano de 1989, dos quais 9,1\% não foram registrados nos cartórios de Maringá. 
Do total de 4.849 registros civis, de filhos de mulheres residentes, efetuados nos cartórios do Município, 414 não corresponderam à população estudada. Destes, 137 foram nascimentos ocorridos em locais diferentes ao do estudo, isto é, 20 crianças nasceram em domicílio e 117 em hospitais de outros municípios. Embora a legislação brasileira estabeleça que o registro seja dado de acordo com o local de ocorrência do evento, nem sempre estas determinações são seguidas. As demais não participaram do estudo porque, segundo anotação hospitalar, procediam de outros municípios ou não foram localizadas entre as nascidas no hospital especificado. Nada pode assegurar que a informação quanto ao local de nascimento, no cartório, não seja correta, mas a não exigência de documentos comprobatórios que atestem o nascimento e o verdadeiro nome da mãe, no momento do registro, possibilitam incorreçōes ou ainda falsificação de informaçð̃es, apesar do caráter ilegal. No presente estudo, dois fatos curiosos valem ser mencionados: o primeiro refere-se a situação na qual a parturiente deu à luz a um nascido morto, comprovadamente registrado como natimorto no cartório; no entanto, esta mesma pessoa configura na listagem do cartório como mãe de uma criança nascida um mês após o evento citado, sugerindo possibilidade de adoção de uma criança, sem via judicial; o segundo refere-se a um duplo registro. $O$ declarante, pai da criança, inscreve em dois cartórios, no mesmo dia ao do nascimento, uma criança que recebe o mesmo nome nos dois locais, configurando uma situação bastante incomum, para a qual poucas explicações poderiam ser levantadas, pois não existem vantagens aparentes para tal atitude.

Estas questōes, aqui levantadas, reforçam a importância da utilização de declaração de nascimento, documento este que propicia um salto qualitativo em nível das estatísticas vitais. Além disso, a não-existência de um documento que ateste o nascimento e sua respectiva filiação pode facilitar as adoções ilegais. Das 145 crianças declaradas, no cartório, como nascidas nos hospitais do $\mathrm{Mu}$ nicípio, verificou-se que 66 não foram identificadas nos registros hospitalares. Esta não exigência pode favorecer o registro, por exemplo, de netos pelas avós, seja por razões relacionadas à ilegitimidade ou ainda por serem filhos de mulheres muito jovens, sem vínculo marital.

Assim, a taxa de sub-registro obtida, para Maringá, pode ser considerada uma taxa máxima. A título de ilustração, se as 66 crianças referidas correspondessem realmente à população estudada, a taxa de sub-registro seria 7,6\% e nåo $9,1 \%$.

Uma outra questão que diz a favor de uma possível percentagem menor de crianças sem re- gistro, refere-se à possibilidade de mulheres nãoresidentes, de melhor poder aquisitivo, fornecerem no hospital endereço de referência em Maringá como o de sua residência, mas efetuarem o registro no cartório da localidade que residem.

A taxa estimada no presente estudo assemelhase à obtida por Simões ${ }^{11}$, para a Região Sul, que comparando o número de nascidos vivos obtidos em duas pesquisas da PNAD (Pesquisa Nacional de Amostra de Domicílio) com o número de nascidos vivos coletados diretamente do registro civil, constatou uma taxa de sub-registro, segundo regið̋es brasileiras, variando de 53,3\% na Região Norte a $10 \%$ na Região Sul, em 1987. Barros e col. ${ }^{2}$ revelaram taxa de sub-registro de $7,8 \%$ para Pelotas, em 1982, obtida através da revisão das notificações de nascimentos encaminhadas à Secretaria de Saúde e do Meio Ambiente do Estado, pelos hospitais.

O estudo realizado por Portela ${ }^{6}$ retrata uma realidade bastante diferente, onde $68,4 \%$ das crianças nascidas vivas no Município de Piripiri, Piauí, não foram registradas no cartório. Dentre as razões do não registro, aponta o estado marital da mãe, a falta de instrução e a exigência do pagamento.

Simős ${ }^{11}$, comparando o número de nascidos vivos inscritos em estabelecimentos de saúde do país, com o número de registrados oficialmente (período 1980-88), evidencia uma piora na cobertura dos dados sobre nascimentos pelo Registro Civil durante 1983 e 1984, período no qual a crise econômica foi mais intensa.

O que se observa em Maringá, entre as crianças nascidas nos hospitais, em 1989, é que a estratificação dos dados de registro segundo variáveis socioeconômicas revela diferenças consideráveis. Assim, observa-se que a proporção de registro segundo sexo diferiu pouco, $90,8 \%$ das meninas e $91,2 \%$ dos meninos foram registrados, resultado este esperado, tendo em vista os valores estabelecidos pela sociedade brasileira que, via de regra, não valoriza crianças de determinado sexo em detrimento ao outro. No entanto, o mesmo não ocorre em relação à idade da mãe. Conforme se observa na Tabela 2, a taxa de sub-registro diminui à medida que aumenta a idade da mãe. A maior taxa foi verificada em filhos de mulheres entre 13 e 14 anos $(21,4 \%)$, seguida pelas de 15 a 19 anos $(11,5 \%)$, índice que diminui consideravelmente em crianças cujas mães têm entre 30 a 39 anos $(5,7 \%)$. Houve associação estatisticamente significante $(\alpha=0,05)$ entre sub-registro e mãe adolescente. Uma possivel explicação poderia estar relacionada à situação marital e socioeconômica das mães adolescentes. Na Tabela 3 verifica-se que, à medida que aumenta o número de filhos tidos anteriormente, diminui a proporção de registros efetuados. 
Tabela 2. Nascidos vivos em hospitais, filhos de mulheres residentes, segundo idade da mâe e registro civil. Maringá-PR, 1989. (№ $\Theta \%$ )

\begin{tabular}{|c|c|c|c|c|c|c|}
\hline \multirow{3}{*}{$\begin{array}{l}\text { Idade da } \\
\text { mãe } \\
\text { (anos) }\end{array}$} & \multicolumn{4}{|c|}{ Registro Civil } & & \\
\hline & \multicolumn{2}{|c|}{ Sim } & \multicolumn{2}{|c|}{ Não } & \multicolumn{2}{|c|}{ Total } \\
\hline & $\mathrm{N}^{2}$ & $\%$ & $\mathrm{~N}^{2}$ & $\%$ & $N^{2}$ & $\%$ \\
\hline $\begin{array}{l}13 \text { a } 14 \\
15 \text { a } 19 \\
20 \text { a } 29 \\
30 \text { a } 39 \\
40 \text { a } 49\end{array}$ & $\begin{array}{r}11 \\
661 \\
2829 \\
874 \\
56\end{array}$ & $\begin{array}{l}78,6 \\
88,5 \\
90,6 \\
94,3 \\
93,3\end{array}$ & $\begin{array}{r}3 \\
86 \\
293 \\
53 \\
4\end{array}$ & $\begin{array}{r}21,4 \\
11,5 \\
9,4 \\
5,7 \\
6,7\end{array}$ & $\begin{array}{r}14 \\
747 \\
3122 \\
927 \\
60\end{array}$ & $\begin{array}{l}100,0 \\
100,0 \\
100,0 \\
100,0 \\
100,0\end{array}$ \\
\hline Total & 4431 & 91,0 & 439 & 9,0 & $4870^{*}$ & 100,0 \\
\hline
\end{tabular}

- Excluídos 6 casos cuja idade da mãe é ignorada.

Tabela 3. Nascidos vivos em hospitais, filhos de mulheres residentes, segundo número de filhos tidos anteriormente $\theta$ registro civil. Maringá-PR, 1989. ( $\mathrm{N}^{2} \Theta \%$ )

\begin{tabular}{|c|c|c|c|c|c|c|}
\hline \multirow{3}{*}{$\begin{array}{l}N^{2} \text { de filhos } \\
\text { tidos anteri- } \\
\text { ormente }\end{array}$} & \multicolumn{4}{|c|}{ Registro Civil } & & \\
\hline & \multicolumn{2}{|c|}{ Sim } & \multicolumn{2}{|c|}{ Não } & \multicolumn{2}{|c|}{ Total } \\
\hline & $N^{0}$ & $\%$ & $N^{2}$ & $\%$ & $N^{2}$ & $\%$ \\
\hline $\begin{array}{c}\text { Nenhum } \\
1 \\
2 \\
3 e 4 \\
5 \text { a } 14\end{array}$ & $\begin{array}{r}1547 \\
1103 \\
523 \\
156 \\
41\end{array}$ & $\begin{array}{l}93,5 \\
92,9 \\
92,2 \\
86,2 \\
71,9\end{array}$ & $\begin{array}{r}108 \\
84 \\
44 \\
25 \\
16\end{array}$ & $\begin{array}{r}6,5 \\
7,1 \\
7,8 \\
13,8 \\
28,1\end{array}$ & $\begin{array}{r}1655 \\
1187 \\
567 \\
181 \\
57\end{array}$ & $\begin{array}{l}100,0 \\
100,0 \\
100,0 \\
100,0 \\
100,0\end{array}$ \\
\hline Total & 3370 & 92,4 & 277 & 7,6 & $3647^{*}$ & 100,0 \\
\hline
\end{tabular}

- Excluídos 1229 casos, cujo número de filhos tidos anteriormente era desconhecido.

Enquanto apenas $6,5 \%$ dos primeiros filhos deixaram de ser registrados, $28,1 \%$ das crianças que correspondiam a sexto filho ou mais não foram oficialmente registrados. Associação significante $(\alpha=0,05)$ foi detectada entre mães que tinham até dois filhos e registro de nascimento. Hipótese de associação entre alta paridade e baixo nível socioeconômico pode ser aventada.

Outras variáveis que guardam relação com o nível econômico também revelam estas diferenças. O local em que $\propto$ correu o parto, por exemplo, devido a sua seletividade, apresenta interessantes diferenças (Tabela 4).

O hospital 1, atendendo somente clientela coberta pelo Sistema Previdenciário oficial, teve uma taxa de sub-registro de $19,4 \%$ e, em contrapartida, a menor foi observada no hospital 7 , seguido pelo hospital 3, que atenderam maior proporção de particulares e seguradas pelo sistema privado.

Ainda ilustrando as mesmas questões, observa-se, na Tabela 5, que $21,2 \%$ das mães "indi-
Tabela 4. Nascidos vivos em hospitais, filhos de mulheres residentes, segundo hospital e registro civil. Maringá-PR, 1989. ( $\left.\mathrm{N}^{2} \mathrm{e} \%\right)$

\begin{tabular}{lrrrrrr}
\hline & \multicolumn{3}{c}{ Registro Civil } & \multicolumn{2}{c}{ Total } \\
\cline { 2 - 6 } & \multicolumn{2}{c}{ Sim } & \multicolumn{2}{c}{ Não } & \multicolumn{2}{c}{ To } \\
\cline { 2 - 6 } Hospital & \multicolumn{1}{c}{$N^{2}$} & $\%$ & No & $\%$ & \multicolumn{1}{c}{$N^{2}$} & $\%$ \\
\hline 1 & 237 & 80,6 & 57 & 19,4 & 294 & 100,0 \\
2 & 760 & 90,7 & 78 & 9,3 & 838 & 100,0 \\
3 & 438 & 92,4 & 36 & 7,6 & 474 & 100,0 \\
4 & 435 & 87,5 & 62 & 12,5 & 497 & 100,0 \\
5 & 71 & 75,5 & 23 & 24,5 & 94 & 100,0 \\
6 & 591 & 90,6 & 61 & 9,4 & 652 & 100,0 \\
7 & 1900 & 93,7 & 127 & 6,3 & 2027 & 100,0 \\
\hline Total & 4432 & 90,9 & 444 & 9,1 & 4876 & 100,0 \\
\hline & & & & & &
\end{tabular}

Tabela 5. Nascidos vivos em hospitais, filhos de mulheres residentes, segundo vínculo previdenciário e registro civil. Maringá-PR, 1989. ( $\left.{ }^{2} \theta \%\right)$

\begin{tabular}{|c|c|c|c|c|c|c|}
\hline \multirow{3}{*}{$\begin{array}{l}\text { Vinculo } \\
\text { previdenciário }\end{array}$} & \multicolumn{4}{|c|}{ Registro Civil } & & \\
\hline & \multicolumn{2}{|c|}{ Sim } & \multicolumn{2}{|c|}{ Não } & \multicolumn{2}{|c|}{ Total } \\
\hline & $N^{2}$ & $\%$ & $\mathrm{~N}^{2}$ & $\%$ & $N^{2}$ & $\%$ \\
\hline \multirow{2}{*}{$\begin{array}{l}\text { Indigência } \\
\text { INAMPS } \\
\text { Convênio } \\
\text { privado } \\
\text { Particular }\end{array}$} & $\begin{array}{r}286 \\
2.741\end{array}$ & $\begin{array}{l}78,8 \\
92,1\end{array}$ & $\begin{array}{r}77 \\
234\end{array}$ & $\begin{array}{r}21,2 \\
7,9\end{array}$ & $\begin{array}{r}363 \\
2.975\end{array}$ & $\begin{array}{l}100,0 \\
100,0\end{array}$ \\
\hline & $\begin{array}{l}476 \\
245\end{array}$ & $\begin{array}{l}95,4 \\
93,9\end{array}$ & $\begin{array}{l}23 \\
16\end{array}$ & $\begin{array}{l}4,6 \\
6,1\end{array}$ & $\begin{array}{l}499 \\
261\end{array}$ & $\begin{array}{l}100,0 \\
100,0\end{array}$ \\
\hline Total & 3.748 & 91,5 & 350 & 8,5 & $4.098^{*}$ & 100,0 \\
\hline
\end{tabular}

- Excluídos 778 casos de situação previdenciária ignorada.

gentes" não registraram seus filhos, enquanto que no caso de convênios privados somente $4,6 \%$ deixaram de efetuar o registro (associação estatisticamente significante entre indigência e subregistro de nascimento).

Além dessas questôes, o sub-registro segundo tipo de parto, a princípio sem nenhuma relação, revela taxas distintas (Tabela 6). Das crianças nascidas de parto cesariana, 7,6\% não foram registradas e a taxa foi sensivelmente maior naquelas nascidas de parto normal $(12,7 \%)$. Detectou-se associação estatisticamente significante entre parto normal e sub-registro de nascimento. Estes dados confirmam o possível fator econômico na determinação do tipo de parto, pois nada justifica a maior taxa de sub-registro entre crianças nascidas de parto normal a não ser a condição econômica da criança e de seus familiares.

Um outro fator importante, referente ao registro de nascimentos, é aquele efetuado tardiamente, isto $\varepsilon$, fora do limite legal que é de até 15 dias, 
Tabela 6. Nascidos vivos em hospitais, filhos de mulheres residentes, segundo tipo de parto e registro civil. Maringá-PR, 1989. (Nº\%)

\begin{tabular}{lccccccc}
\hline & \multicolumn{3}{c}{ RegistroCivil } & \multicolumn{2}{c}{ Total } \\
\cline { 2 - 7 } & \multicolumn{2}{c}{ Sim } & \multicolumn{2}{c}{ Não } & \multicolumn{2}{c}{ To } \\
\cline { 2 - 7 } Tipo de parto & $N^{2}$ & $\%$ & $N^{2}$ & $\%$ & $N^{2}$ & $\%$ \\
\hline Normal & 1.250 & 87,3 & 182 & 12,7 & 1.432 & 100,0 \\
Cesariana & 3.181 & 92,4 & 262 & 7,6 & 3.443 & 100,0 \\
\hline Total & 4.431 & 90,9 & 444 & 9,1 & $4.875^{*}$ & 100,0 \\
\hline
\end{tabular}

- Excluido um caso cujo tipo de parto era desconhecido.

para o pai, e 60 dias para todos os demais declarantes. A influência nas estatísticas vitais decorre da distorção existente nos dados quando o número de registros civis efetuados em um determinado ano não corresponde aos nascimentos deste mesmo ano ${ }^{4}$. No caso do Município de Maringá, em $86,8 \%$ dos registros efetuados, o pai da criança foi o declarante e em $11,5 \%$ a mãe (Tabela 7). Ao considerar as determinações legais, quanto aos prazos e declarantes, verifica-se que quando o pai foi o declarante, $90,2 \%$ dos registros deram-se dentro do prazo legal, e $83,5 \%$, quando a mãe foi a declarante. Do total dos registros efetuados, $89,4 \%$ deram-se dentro do prazo legal.

Tabela 7. Nascidos vivos em hospitais, filhos de mulheres residentes, segundo intervalo de tempo entre - nascimento $\theta$ o registro civil $\theta \quad 0$ declarante. Maringá-PR, 1989. ( $N^{2}$ e \%)

\begin{tabular}{|c|c|c|c|c|c|c|c|c|}
\hline \multirow{3}{*}{$\begin{array}{l}\text { Intervalo } \\
\text { de tempo } \\
\text { (dias) }\end{array}$} & \multicolumn{6}{|c|}{ Declarantes } & & \\
\hline & \multicolumn{2}{|c|}{ Pai } & \multicolumn{2}{|c|}{ Mãe } & \multicolumn{2}{|c|}{ Outros } & \multicolumn{2}{|c|}{ Total } \\
\hline & Ne & $\%$ & $N^{2}$ & $\%$ & $N^{2}$ & $\%$ & $\mathbf{N}^{\mathbf{2}}$ & $\%$ \\
\hline 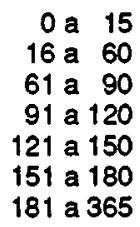 & $\begin{array}{r}3.449 \\
244 \\
37 \\
21 \\
20 \\
16 \\
38\end{array}$ & $\begin{array}{r}90,2 \\
6,4 \\
1,0 \\
0,5 \\
0,5 \\
0,4 \\
1,0\end{array}$ & $\begin{array}{r}177 \\
245 \\
22 \\
17 \\
10 \\
8 \\
26\end{array}$ & $\begin{array}{r}35,0 \\
48,5 \\
4,4 \\
3,4 \\
2,0 \\
1,6 \\
5,1\end{array}$ & $\begin{array}{r}58 \\
12 \\
3 \\
1 \\
2 \\
-1\end{array}$ & $\begin{array}{r}75,3 \\
15,6 \\
3,9 \\
1,3 \\
2,6 \\
- \\
1,3\end{array}$ & $\begin{array}{r}3.684 \\
501 \\
62 \\
39 \\
32 \\
24 \\
65\end{array}$ & $\begin{array}{l}83,6 \\
11,4 \\
1,4 \\
0,9 \\
0,7 \\
0,5 \\
1,5\end{array}$ \\
\hline
\end{tabular}

Total $\quad 3.825100,0505100,077 \quad 100,0 \quad 4.407100,0$

- Excluídos 258 casos cujo declarante e/ou intervalo eram desconhecidos.

Mesmo assumindo que a qualidade das estatísticas oficiais melhorou com o passar dos anos, vários problemas ainda interferem na qualidade das informaçס̄es que têm como fonte de dadoso Registro Civil. Dois problemas, não mensurados quanto à sua intensidade, foram constatados no presente estudo:
- Ocorrência do sub-registro de óbitos de menores de um ano, decorrente do erro na denominação de crianças nascidas vivas que faleceram logo após o nascimento e foram dadas a registro como nascidas mortas. Como consequêencia ocorreram, simultaneamente, o sub-registro de nascido vivo, o sub-registro de óbito de menores de um ano e o super registro de óbito fetal.

- A não exigência de documentos comprobatórios que atestem o nascimento da criança, a verdadeira filiação e outras informaçбes de interesse para o registro civil, pode facilitar alteraçōes na informação. Algumas evidências são sugestivas de que estejam ocorrendo, em Maringá, erros que vão desde alterações nas datas de nascimento, o duplo registro, até adoçőes sem passagem pela via judicial.

Estes dois pontos relativos à qualidade dos dados requerem a implantação de medidas práticas que visem à eliminação gradual desses erros; o primeiro ponto poderia ser pela divulgação intensiva da importância da denominação correta de nascidos vivos e nascidos mortos junto às instituiçð̃es de saúde, associaçōes médicas e escolas de medicina. O segundo, pela implantação da Declaração de Nascimento que, a exemplo da Declaração de Óbito, constitui um formulário padrão a ser devidamente preenchido, no hospital, e de apresentação obrigatória no cartório para efetuar o registro de nascimento. Este documento tem, ainda, a finalidade de alimentar o Subsistema de Informação sobre Nascimentos do Ministério da Saúde (SINASC), em nível nacional. A implantação da Declaração de Nascimento no Município de Maringá contribuiria para correção das distorções mencionadas e propiciaria, quando preenchida de forma completa e correta, a caracterização permanente das crianças e de suas mães segundo variáveis demográficas e epidemiológicas. Através desta monitorização, será possível o conhecimento das crianças com alto risco de morrer, pelas autoridades sanitárias, contribuindo, desta forma, para que açōes decisivas sejam tomadas e um menor número de crianças venha a falecer no seu primeiro ano de vida.

SOUZA, R.K.T. de \& GOTLIEB, S.L.D. [Under registration of hospital live births in an urban area of Southem Brazil, 1989]. Rev. Saúde Pública, 27: 177-84, 1993. With a view to evaluating the real situation of the vital statistics as regards their completeness in the city of Maringá, Paraná State, Brazil, 4,876 hospital live births which occurred during 1989 were studied. The rate of under-registration was estimated as $9.1 \%$, varying according to matemal age, parity and financial condition. The results lead to the hypothesis of an association between under registration and lower socio- 
economical levels. The study also describes all the necessary steps to establish the link between the two sets of events, live birth and legal registration.

Keywords: Underregistration. Birth certificates. Birth rate

\section{Referênclas Blbllografflcas}

1. ALMEIDA, M.M.G. Sub-registro de nascimento em Salvador, Bahia (Brasil), Rev. Saúde Pública, 13: 208-19, 1979.

2. BARROS, F.C. et al. Mortalidade perinatal e infantil em Pelotas, Rio Grande do Sul: nossas estatísticas são confiáveis? Cad. Saúde Pública, 1: 348-58, 1985.

3. LAURENTI, R. et al. Estatisticas de saúde. São Paulo, E.P.U., 1987.

4. MILANESI, M.L \& SILVA, E.P.C. Sub-registro de nascimentos no Distrito de São Paulo. Rev. Saúde Pública, 2: 23-8, 1968.

5. MONTEIRO, A.P.C. Contribuiçāo para o estudo da mortalidade infantil em município do Estado de São Paulo. São Paulo, 1972. [Tese de Doutorado - Faculdade de Saúde Pública USP].

6. PORTELA, M.H.R.B. Sub-registro de nascimentos vivos em Piripiri - Piauí. Rev. Saúde Pública, 23: 493-501, 1989.
7. SAADE, M.J. Verificaçāo estatística do grau de deficiência do registro de nascimentos. Rev. Serv. Saúde Pública, 1: 449-67, 1947 .

8. SCORZELLI Jr., A. Coleta de dados vitais em pequenas localidades. Rev. Serv. Saúde Pública, 1: 397-432, 1947.

9. SECRETARIA DE ESTADO DA SAÚDE. Sub-registro de nascimentos e obitos. Porto Alegre, 1976.

10. SILVEIRA, M.H. \& LAURENTI, R. Os eventos vitais: aspectos de seus registros e inter-relaçōes da legislação vigente com as estatísticas de saúde. Rev. Saúde Pública, 7: 37-50, 1973.

11. STMOES, C.C., org. Perfil estatístico de crianças e mäes no Brasil: mortalidade infantil e saúde na década de 80. Rio de Janeiro, IBGE, 1989.

12. SUAREZ, L.A. Sub-registro de nascimento. São Paulo, 1968. [Dissertação de Mestrado - Faculdade de Saúde Pública de USP].

13. UNIVERSIDADE DE SÃO PAULO. Faculdade de Saúde Pública. Presidente Wenceslau: trabalho de campo multiprofissional. São Paulo, 1972. (Trabalho de Campo Multiprofissional - Curso de Especialização em Saúde Pública, 1972).

Recebido para publicação em 3.11.1992

Reapresentado em 15.3.1993

Aprovado para publicaça em 2.4.1993 